\title{
THE REAL IN THE VIRTUAL. THE 3D MODEL IN THE CULTURAL HERITAGE SECTOR: THE TIP OF THE ICEBERG
}

\author{
S. Pratali Maffei ${ }^{1}$, E. Canevese ${ }^{2}$, T. De Gottardo ${ }^{3}$ \\ ${ }^{1}$ Department of Engineering and Architecture, University of Trieste, Italy, pratali@units.it \\ ${ }^{2}$ CEO Virtualgeo, Sacile (PN), Italy, erminio.canevese@virtualgeo.it \\ ${ }^{3}$ R\&D Manager Virtualgeo, Sacile (PN), Italy, tiziano.degottardo@virtualgeo.it
}

KEY WORDS: BIM for Cultural Heritage (HBIM), Advanced 3D, conservation, architectural heritage, Virtualgeo, Aquileia, Roman fluvial port

\begin{abstract}
:
The twenty-year and interdisciplinary research activity carried out by Virtualgeo has focused on the development of new methods and tools for 3D modeling that go beyond the simple digital-virtual reconstruction of solid modelling, in order to realize three-dimensional informative and photogrammetric representations that faithfully reproduce reality. These so called Advanced 3D models are the basis for carrying out metrological investigations to support the design and the BIM database population. In particular, in this paper we will deal with the segmentation tool, which allows the classification of the photogrammetric 3D model (material, degradation and chronological features). In detail, we will illustrate the collaboration experience between Virtualgeo and the University of Trieste, course in Technologies for the conservation and enhancement of architectural heritage of the Master's Degree in Architecture. The experience focused on the study of the archaeological site of the Roman river port of Aquileia, which Advanced 3D model was supplied by Virtualgeo. Firstly, the work focused on the informative contents necessary for the subsequent elaborations (different types of materials, alteration/degradation forms), starting from the use of coded lexicons (UNI 11182/2006). Subsequently, the quantitative data were associated to each category of homogeneous elements, obtainable from the segmentation ("mapping") of the 3D model. This experience gave the chance to test the EasyCUBE PRO software: it was gradually adapted to the specific needs emerged both during the analysis of the site and the definition of conservation interventions, so as the outputs that can be generated after the elaboration of the Advanced 3D model.
\end{abstract}

\section{INTRODUCTION}

The research and development activities described in this article originate from a basic principle, described by the following sentence: "The correct elaboration of the restoration project is not able to leave the deep knowledge of the artefact matter of the research out of consideration, since only after the knowing process the intervention can be "guided" both at the theoretical and procedural level, reducing all the while the "risks" of the arbitrariness of the project design" (Franceschi et al., 2007).

Starting from this principle Virtualgeo srl, thanks to the experience gained since the mid-80s in the topographic and virtual reality and the acquisition of a LIDAR system (Laser Imaging Detection and Ranging), has started a research activity in the field of data management processes and software in order to faithfully reproduce the objects (buildings, infrastructures, territory) from a geometric point of view.

The title of this paper - "Reality inside virtuality" - indicates the possibility of combining highly accurate three-dimensional digital models with 3D models obtained with traditional virtual reality techniques, such as the $3 \mathrm{D}$ models underlying the BIM (Building Information Model) processes.

The traditional 3D modeling techniques include: the volumetric one (Metaball for fluid simulation); the surfaces modeling (mesh), based on nurbs technique (for complex shapes and in particular for morphing interventions) or polygons (used in different areas and in particular in the field of geomatics); the solid modeling, implemented with parametric functionalities from the end of the $80 \mathrm{~s}$, which allow to relate the elements that constitute the 3D model with physical and geometrical parameters, linking them to searchable geospatial databases.

In the field of geomatics, volumetric modeling methods and nurbs have been abandoned for several reasons. The following are the differences between solid (also parametric) and polygonal (mesh) modeling.
3D modeling and in particular reverse modeling (representation of an existing entity) show limitations regarding the representation of any architectural, archaeological or land object. Consider, for example, the solid three-dimensional representation of a Venetian palace, full of imperfections (depressions of the floors, out of plumb and bulging of the walls). This representation will not be a faithful copy of the building but a plausible copy, as if it were a new construction. This means that the BIM system, created to simulate new buildings and manage their construction and maintenance, is not intended to reproduce the existing artifacts in a faithful way to the real and even today its use in the cultural heritage, despite of the introduction of the prefix " $\mathrm{H}$ " (Historical or Heritage), it encounters enormous difficulties in this respect.

For this reason, Virtualgeo srl started research and development activities for the realization of 3D modeling processes and techniques to contribute to the creation of $3 \mathrm{D}$ models faithful to the real and semantic. The results of these researches actualized in the creation of $3 \mathrm{D}$ models with polygonal surfaces of high accuracy, comparable to the TIN (Triangulated Irregular Network) models, which can be managed by any computer and called Advanced 3D, in reference to the research program of the European Commission Horizon 2020: REFLECTIVE-7-2014: Advanced 3D modeling for accessing and understanding European cultural assets.

The results of these activities were presented at TECHA2008 Technologies Exploitation for the Cultural Heritage Advancement, Rome, 10th-11th March 2008.

The call REFLECTIVE-7-2014 provided a particular attention to the innovative modeling techniques and to the methods and tools used in the survey activities; in particular, for the conservation and restoration activities, these tools must take into account the geometries and their imperfections, the materials and their state of alteration-degradation, the stratigraphic analysis, etc. The current survey approach, consistent with that adopted in the 
analogical era, is set in two phases: the acquisition of data and the bi-dimensional or three-dimensional rendering of the same.

Today, thanks to the Advanced 3D and its high geometric and photogrammetric accuracy, the survey can integrate a third step called "segmentation" or classification of the information concerning, in addition to the morphometries and morphologies of the built, also the aspects mentioned above (materials, alteration-degradation status, stratigraphic analysis).

This paper will illustrate also a case study regarding the Roman fluvial port of Aquileia in order to show how Advanced 3D technology can support and be complementary to HBIM technology for the study, conservation and digital cataloging of cultural heritage.

\section{ACQUISITION OF DATA}

The first phase consists in choosing the most suitable survey tool, based on the object to be detected and the required accuracy. Actually, the object could be made up of sub-components with different characteristics and variable required accuracy. Therefore, the first step is to design the survey in such a way as to choose and use all the most suitable survey tools according to the area of interest.

Table 1 summarizes the types of devices currently available, their characteristics and the scope of use (UACE, 2018).

As previously mentioned, it is important to define the objectives of a survey and consequently to decide the degree of accuracy to be achieved for the 3D model. Depending on whether it is a small artefact (sculpture, design object, etc.), a large object (monument, historic building, etc.), or an open-air area, it is vital to choose the most suitable instrument. In this paper, the most appropriate survey technologies will be listed, with reference to the restoration interventions on buildings and open-air areas, as in the case of the Roman river port of Aquileia.

As has been reported, in 3D solid modeling (BIM), the degree of achievable accuracy can never be high (Canevese et al., 2017). In the case of Advanced 3D models, on the other hand, both the choice of measurement technology and the survey method are important: the objective is to obtain a $3 \mathrm{D}$ model with a high degree of accuracy that allows dimensional explorations (metrology) and analysis based on the chromatic feature (see Table 2).

Thanks to the experience gained in the survey activities and to the several experiments and studies carried out for research purposes, below are some useful expedients in order to obtain a valid survey:

- $\quad$ using "phase-shift" laser scanners because they are more precise and use a higher number of measurements;

- $\quad$ avoid moving systems: perform static scans in order to prevent acquisitions from being affected by errors due to the movement and/or the supporting technologies;

- $\quad$ perform an accurate topographic survey to support laser scans, polygonations and detailed survey of reference points, which must be positioned appropriately in order to align point clouds;

- $\quad$ avoid relying entirely on automatic point cloud alignment systems.

The advantages offered by an Advanced 3D model are unexpected and the realization cost (in any case in line with the other modeling techniques) is amply repaid in the subsequent design and monitoring activities, as shown in Table 2 regarding the comparison of the feasible activities depending on the different types of 3D models.

\begin{tabular}{|c|c|c|c|c|}
\hline \multirow{2}{*}{ Measuring technologies } & \multicolumn{4}{|c|}{ Characteristics } \\
\hline & & type of measurement & supporting technology & number of points detected \\
\hline \multicolumn{5}{|l|}{$2 \mathrm{D}$ and $2.5 \mathrm{D}$ cartography } \\
\hline Total station & ()ㅏㄹ & Direct & none & single \\
\hline Global Positioning System & es & Direct & none & single \\
\hline "Phase-shift" Laser scanner & $\underline{\underline{E}}$ & Direct & none & up to $1.000 .000 / \mathrm{sec}$ \\
\hline "Time-of-flight" laser scanner & il & direct & none & up to $400.000 / \mathrm{sec}$ \\
\hline $\begin{array}{l}\text { Moving laser scanner } \\
\text { (car, cart, operator) }\end{array}$ & 安 & direct & GPS, IMU, odometer & up to $400.000 / \mathrm{sec}$ \\
\hline $\begin{array}{l}\text { Moving laser scanner } \\
\text { (airplane, helicopter) }\end{array}$ & 透 & direct & GPS, IMU & up to $200.000 / \mathrm{sec}$ \\
\hline $\begin{array}{l}\text { Moving laser scanner } \\
\text { (APR drone) }\end{array}$ & 彩 & direct & GPS, IMU & up to $1.000 .000 / \mathrm{sec}$ \\
\hline $\begin{array}{l}\text { Aerial photography } \\
\text { (APR drone) }\end{array}$ & 穿 & indirect (epipolar geometry) & ground control points & image resolution (pixels) \\
\hline Photographic shooting & 0 & indirect (epipolar geometry) & ground control points & image resolution (pixels) \\
\hline $\begin{array}{l}\text { Triangulation scanning } \\
\text { (laser, structured light) }\end{array}$ & $\sqrt{6}$ & direct & none & up to $1.000 .000 / \mathrm{sec}$ \\
\hline “Single-beam” bathymetry & $\sin ^{1}$ & direct & none & single \\
\hline "Multi-beam" bathymetry & 霖 & direct & none & up to $200.000 / \mathrm{sec}$ \\
\hline
\end{tabular}

Table 1. Types of acquisition tools, characteristics and scope of use

\subsection{Rendering of the Advanced 3D model}

The Advanced 3D models are obtained from the raw data collected in the field, using a series of modeling techniques and technologies developed ad hoc that allow to obtain a 
lightweight and accurate at the same time $3 \mathrm{D}$ data, which is informative and photogrammetric. Similarly to what happens during the data acquisition phase, designing the rendering in order to choose and use all the most suitable 3D modeling tools according to the area of interest is essential, also in this case.
Below is a table (Table 2) that summarizes the types of modeling tools available to date, their characteristics and the scope of use (data taken from Canevese et al., 2017).

\begin{tabular}{|c|c|c|c|c|c|c|}
\hline & \multirow{2}{*}{ Description of the activity } & \multicolumn{5}{|c|}{ Types of 3D models } \\
\hline & & $3 \mathrm{D} \mathrm{VR}$ & TIN & BIM & LIM $®$ & $\mathrm{PDM}{ }^{\circledR}$ \\
\hline 2D elaboration & & $\bullet$ & $\bullet$ & $\bullet$ & $\bullet$ & $\bullet$ \\
\hline Static and dyne & isual simulations & $\bullet$ & $\bullet$ & $\bullet$ & $\bullet$ & $\bullet$ \\
\hline 3D Informativ & & & & $\bullet$ & $\bullet$ & $\bullet$ \\
\hline Geo-reference & imedia database & & (2) & $\bullet$ & $\bullet$ & $\bullet$ \\
\hline $\begin{array}{l}\text { Automatic eva } \\
\text { architectural, s }\end{array}$ & $\begin{array}{l}\text { of the surface parameters belonging to } \\
\text { ral, decorative elements, etc. }\end{array}$ & & & (2) & $\bullet$ & $\bullet$ \\
\hline $\begin{array}{l}\text { Validation of } t \\
\text { reports illustra } \\
\text { the entire mod }\end{array}$ & $\begin{array}{l}\text { model by using photographic and alphanumeric } \\
\text { e accuracy of the 3D surfaces and the reliability of }\end{array}$ & & () & & $\bullet$ & $\bullet$ \\
\hline $\begin{array}{l}\text { Geometric ana } \\
\text { model both ma } \\
\text { elements and c }\end{array}$ & $\begin{array}{l}\text { f the deformations of each element of the } 3 \mathrm{D} \\
\text { or with an automated process on the entire set of } \\
\text { n of photographic and alphanumeric reports }\end{array}$ & & () & & $\bullet$ & $\bullet$ \\
\hline $\begin{array}{l}\text { Analysis of the } \\
\text { and creation of }\end{array}$ & $\begin{array}{l}\text { ioration and degradation based on the } 3 \mathrm{D} \text { model } \\
\text { graphic and alphanumeric reports }\end{array}$ & & () & & & $\bullet$ \\
\hline $\begin{array}{l}\text { Segmentation } \\
\text { stratigraphy an }\end{array}$ & $\begin{array}{l}\text { 3D model on the basis of chronological } \\
\text { tion of photographic and alphanumeric reports }\end{array}$ & & () & & & $\bullet$ \\
\hline $\begin{array}{l}\text { High-resolutio } \\
\text { cross-sections, }\end{array}$ & $\begin{array}{l}\text { hic photogrammetric representations of plans, } \\
\text { views and 3D sections }\end{array}$ & & (0) & & & $\bullet$ \\
\hline - Full funct & | () Limited functionality depending on the number & olvoon & $3 \mathrm{D} \mathrm{n}$ & nd/or & erative & plexity \\
\hline $3 \mathrm{D} V \mathrm{VR}$ & $\begin{array}{l}\text { 3D VR models are created with solid modelling tec } \\
\text { Cinema4D, etc...) or technical drawing (Autocad, } \\
\text { because of the solid modelling techniques, cannot } \\
\text { plumbs, depressions, outcroppings) nor chromat } \\
\text { simplified copies of the original. }\end{array}$ & $\begin{array}{l}\text { niques usit } \\
\text { icsCad, Sk } \\
\text { ccurately r } \\
\text { of an act }\end{array}$ & $\begin{array}{l}\text { softwa } \\
\text { IUp, et } \\
\text { eate the } \\
\text { object. }\end{array}$ & $\begin{array}{l}\text { r virtua } \\
\text { ike BII } \\
\text { jueness } \\
\text { this re }\end{array}$ & $\begin{array}{l}\text { ality }(\mathrm{Ma} \\
\text { hodels, } 3 \mathrm{I} \\
\text { ither geor } \\
\text { n 3D VF }\end{array}$ & $\begin{array}{l}\text { 3Dstudio, } \\
\text { R models, } \\
\text { tric (out of } \\
\text { nodels are }\end{array}$ \\
\hline TIN & $\begin{array}{l}\text { Triangular Irregular Network is the 3D model gene } \\
\text { triangulation, from the name of the soviet mathen } \\
\text { three-dimensional (3D, normally named mesh) or } 2 \\
\text { Terrain Model). TIN is also informative when it } \\
\text { elements (e.g. www.geomaticscube.com/landscape }\end{array}$ & $\begin{array}{l}\text { ated with th } \\
\text { ticians Bo } \\
\text { D when it } \\
\text { cludes the }\end{array}$ & $\begin{array}{l}\text { Elauna } \\
\text { Nikola } \\
\text { cerns tl } \\
\text { smenta }\end{array}$ & $\begin{array}{l}\text { ngulati } \\
\text { Delone, } \\
\text { presenta } \\
\text { classifi }\end{array}$ & $\begin{array}{l}\text { (also kno } \\
90-1980) \\
n \text { of the te } \\
\text { ion) of th }\end{array}$ & $\begin{array}{l}\text { as Delone } \\
\text { CIN can be } \\
\text { in (Digital } \\
\text { constituent }\end{array}$ \\
\hline BIM & $\begin{array}{l}\text { BIM model is the 3D model underlying the BIM } \\
\text { created with solid 3D parametric modelling tech } \\
\text { different solids that constitute the model and assoc } \\
\text { of the solid modelling techniques, both BIM mode } \\
\text { uniqueness neither geometric (out of plumbs, depr } \\
\text { this reason BIM models are simplified copies of th }\end{array}$ & $\begin{array}{l}\text { Building Ir } \\
\text { ques. Para } \\
\text { te them wi } \\
\text { s and } 3 \mathrm{D} \text { V } \\
\text { sions, outc } \\
\text { original. }\end{array}$ & $\begin{array}{l}\text { mation } \\
\text { ric mo } \\
\text { eometr } \\
\text { nodels } \\
\text { jings) } 1\end{array}$ & $\begin{array}{l}\text { lelling- } \\
\text { ig cons } \\
\text { ind phy } \\
\text { ot able } \\
\text { rromati }\end{array}$ & $\begin{array}{l}\text { cesses. } \\
\text { in conn } \\
\text { al parame } \\
\text { accuratel } \\
\text { f an actua }\end{array}$ & $\begin{array}{l}\text { M model is } \\
\text { ing all the } \\
\text { s. Because } \\
\text { ecreate the } \\
\text { rtefact. For }\end{array}$ \\
\hline LIM® & $\begin{array}{l}\text { Lidar Information Model is the 3D model resultit } \\
\text { have been designed and developed by Geomatics } \\
\text { LIM model accurately reproduces geometric chara } \\
\text { (chronological, material and structural) to every si } \\
\text { 3D LIM models allow automated metrological an } \\
\text { single element. }\end{array}$ & $\begin{array}{l}\text { from surf } \\
\text { UBE, App } \\
\text { teristics of } \\
\text { le element } \\
\text { lyses (out }\end{array}$ & $\begin{array}{l}\text { model } \\
\text { Resea } \\
\text { object } \\
\text { like } 3 \mathrm{D} \\
\text { lumbs }\end{array}$ & $\begin{array}{l}\text { techniq } \\
\text { Divisior } \\
\text { it assoc } \\
\text { dels cre } \\
\text { ression }\end{array}$ & $\begin{array}{l}\text { and tech } \\
\text { f Virtuals } \\
\text { es specifi } \\
\text { d with sol } \\
\text { utcroppir }\end{array}$ & $\begin{array}{l}\text { logies that } \\
\text { S.r.l. 3D } \\
\text { nformation } \\
\text { modelling, } \\
\text { ) on every }\end{array}$ \\
\hline $\mathrm{PDM} \circledast$ & $\begin{array}{l}\text { Photo 3D Model is a 3D photogrammetric moc } \\
\text { Research Division of Virtualgeo srl 3D PDM m } \\
\text { direct application of photographic images on the } 3 \\
\text { allow metrological, chronological, deterioration at } \\
\text { the possibility to create automated photographic ar }\end{array}$ & $\begin{array}{l}1 \text { designed } \\
\text { lel is obtai } \\
\text { TIN and } \\
\text { lyses etc., } \\
\text { illustrativ }\end{array}$ & $\begin{array}{l}\text { d deve } \\
\text { by pho } \\
\text { I mode } \\
\text { ctly on } \\
\text { ports to }\end{array}$ & $\begin{array}{l}\text { d by } G \\
\text { ammetr } \\
\text { 3D photo } \\
\text { er with }\end{array}$ & $\begin{array}{l}\text { naticsCU } \\
\text { echnique } \\
\text { mmetric } \\
\text { and is as } \\
\text { tric calcu }\end{array}$ & $\begin{array}{l}\text { Epplied } \\
\text { hrough the } \\
\text { M models } \\
\text { ciated with } \\
\text { ions. }\end{array}$ \\
\hline
\end{tabular}

Table 2. Types and characteristics of the 3D models 
The resulting 3D model is accurate and segmented into the elements that is composed by. The elements follow a tree structure hierarchy (Fig. 3). This is a very important feature, because it makes the model easily manageable and consultable (it is possible to choose which elements to display in order to proceed to a specific analysis) and it allows the automatic calculation of both surfaces and volumes of every object, to support the metric estimates.

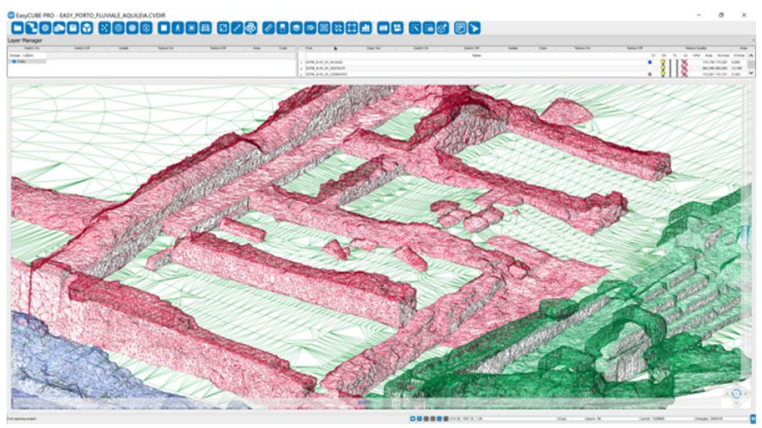

Figure 3. Detail of a section of the Advanced 3D model without textures of the Roman river port of Aquileia

For this reason, the Advanced 3D model is defined as "informative". Besides the accuracy of the data and its segmentation, the Advanced 3D model is characterized by the photogrammetric features (in this case it is described as PDM - Photographic 3D Model). Actually, the "covering" of the Advanced 3D model takes place through digital photogrammetry processes based on the identification of three-dimensional homologous points, in order to obtain an accurate three-dimensional chromatic representation (Fig. 4). This procedure is essential in order to carry-out segmentations and to associate information of various kind to each single element of the 3D model, such as: physical material characteristics, degradation state, level of cracking and stratigraphic features (Canevese et al., 2017).

\section{HBIM: BIM FOR THE CULTURAL HERITAGE}

BIM (Building Information Modeling) is a method designed for optimizing planning, construction and construction management by means of a software. This approach implies the creation of a 3D model, the collection of every information concerning the artefact and the sharing of this information in order to improve and facilitate the design and implementation phases thanks to the resulting simplified collaboration among all the professionals involved.

The BIM was actually born at the end of the $80 \mathrm{~s}$, starting from the idea of a virtual building to be implemented and it has developed in support of the planning, realization and

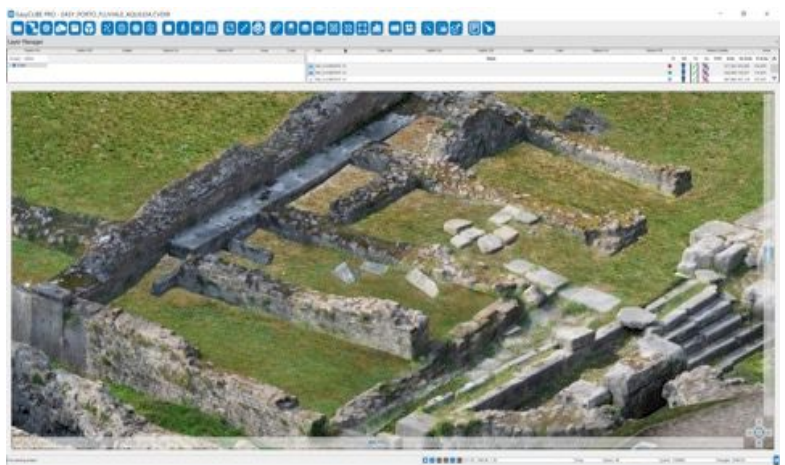

Figure 4. Detail of the section (see Fig. 3) after the application of the corresponding textures (Roman river port of Aquileia) management of new works. BIM fits perfectly with the coordination of new works because the suitable level of discretization in the modeling matches the results obtained with the parametric modeling techniques usually adopted in BIM.

Only in the last few years HBIM (Heritage BIM) is catching on. The acronym HBIM stands for the adoption of BIM techniques for restoration projects of cultural heritage. In the cultural heritage field there is a lot of information to be collected and shared among various professionals. Nevertheless, HBIM is still in its early days and experts perpetually face major problems due to the lower level of acceptable geometric discretization for cultural heritage objects (e.g. the floor of a Venetian building and at the ruins of a castle). A recent example regarding the application of HBIM to cultural heritage is Giulio Romano's Pescherie (fish markets) project in Mantova (Olivieri, 2018): while on the one hand it highlighted the potentialities of BIM as a powerful tool to manage information and reduce time and costs, on the other it confirmed the enormous difficulties in generating an accurate and faithful to reality $3 \mathrm{D}$ model owing to the lack of tools.

The research in this field led to some important progress: thanks to their level of accuracy (both geometric and chromatic) and organization, the Advanced 3D models give the opportunity to study and investigate the model and obtain all the necessary information to be transferred during the HBIM process. This is possible thanks to EasyCUBE PRO, stand-alone software of the GeomaticsCUBE Ecosystem (Geomaticscube, 2018) that is able to manage 3D models composed of tens of millions of polygons and thousands of hierarchically organized layers.

EasyCUBE PRO comprises a whole series of tools designed to investigate and study the model (see Fig. 5). In this paper, the tool that allows to segment the Advanced $3 \mathrm{D}$ model is presented.

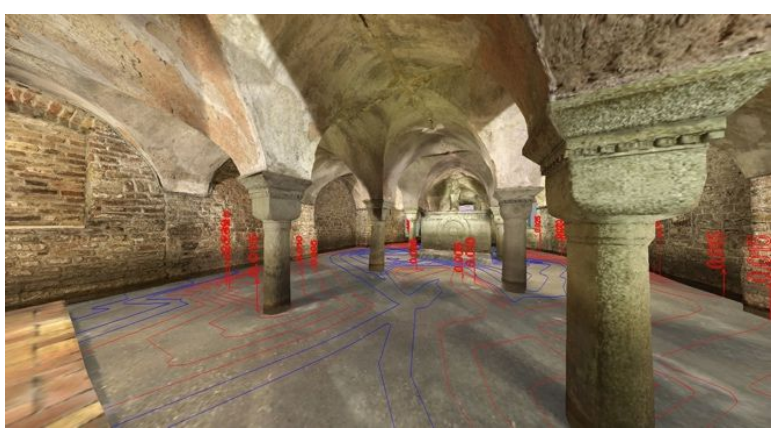

Figure 5. Example of a dimensional analysis of the flooring performed with EasyCUBE PRO: Advanced 3D model of an historical building

\section{THE EASYCUBE PRO SEGMENTATION TOOL TO SUPPORT DEGRADATION ANALYSIS}

The EasyCUBE PRO segmentation tool has been previously defined as "the third step of the survey" and consists in locating the information directly on the $3 \mathrm{D}$ model: this approach represents a radical adjustment compared to the bidimensional analogical representations. This tool was designed to allow the segmentation of the different forms of deterioration of the structure and to create a final report accounting for the partial and total surfaces of the hand-drawn segmentations, in support of the metric and estimative calculations. The segmentations are performed in 3D 
environment, so the calculated surfaces are also represented in $3 \mathrm{D}$.

Before proceeding with the segmentation of the model, it is necessary to prearrange a glossary, that is to say a series of categories and codes describing the various forms of classification to be segmented (material, degradation, chronological, etc.). The EasyCUBE PRO software allows to import predefined glossaries, to customize them according to the characteristics of the object and to save them for later use with other jobs.

Once the glossary has been defined, the following stages of segmentation can start. Below is a description of the two different phases of the segmentation process.

\subsection{Definition of a glossary in EasyCUBE PRO}

Defining a glossary in EasyCUBE PRO consists of mainly defining two lists of elements, following the order shown below. Firstly, the reference groups necessary for the organization of the different types of segmentation must be defined (categories). The introduction of the concept of 'category' is a matter of convenience: since the types of segmentation that may be created could be hundreds, splitting these types of segmentation into a series of groups is particularly useful. Therefore, each group is formed by the types of segmentation with certain characteristics in common. An example of a category could be "Type of stone". Once the diverse groups have been defined, it is possible to outline all the types of segmentation that belong to them, which are called codes. Examples of codes belonging to the "Type of stone" category can be: "Slate", "Sandstone", "Clay", "Basalt", "Conglomerate", etc.

Once the glossary definition phase is over, the actual segmentation phase can begin. It should be noted that, although the segmentation phase is already begun, it is possible to expand the database of categories and codes at any time.

\subsection{The segmentation process ("the third step of the survey") in EasyCUBE PRO}

Essentially, the segmentation process is a simple procedure from an operative point of view, but firstly it is necessary to consistently identify the different areas to be segmented. The segmentation process consists in indicating a sequence of 3D areas of the model characterized by the properties described by the respective code using the EasyCUBE PRO tools. Therefore, every single segmentation implies to follow the sequent process:

1. isolate the layers on which you want to proceed with the sequence of segmentations; then for each segmentation proceed as follow:

2a. choose the category the code belongs to (it acts as a filter for the list of codes to choose from);

2b. choose the code representing the properties to be represented;

2c. draw with the mouse or the pen (for computers equipped with touch display with digitizer) a closed polyline enclosing the area of interest (Fig. 6). If it is not possible to identify the area of interest with a single closed polyline, it is possible to edit the newly created area by drawing one or more closed polylines that can add or subtract parts from the original area.

Thanks to this process, it is then possible to segment the whole 3D model by identifying a series of homogeneous areas characterized by the same properties.

At the end of the segmentation process, the software automatically produces a PDF report containing the graphical representations and the respective positions of the segmentations as well as the partial and total surfaces (the latter also in Excel format) to support the metric calculations (see Fig. 7 and Fig. 8).

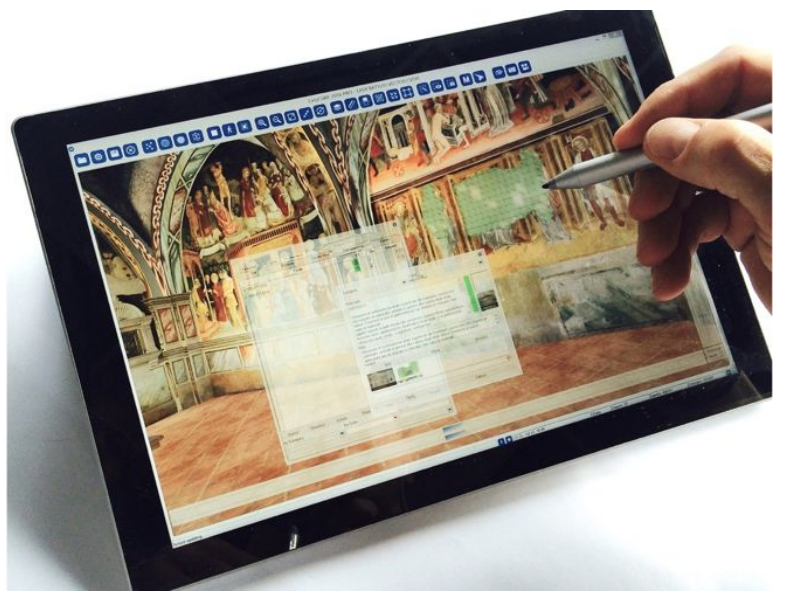

Figure 6. Example of a segmentation process carried out with EasyCUBE PRO tools

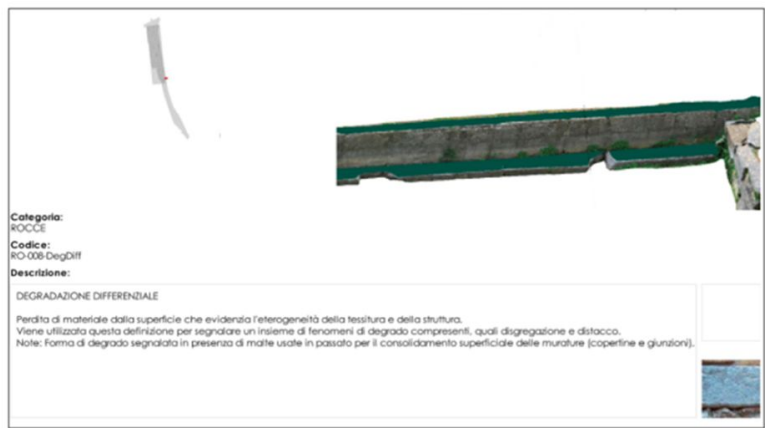

Figure 7. Part of a PDF report automatically generated by EasyCUBE PRO (informative data)

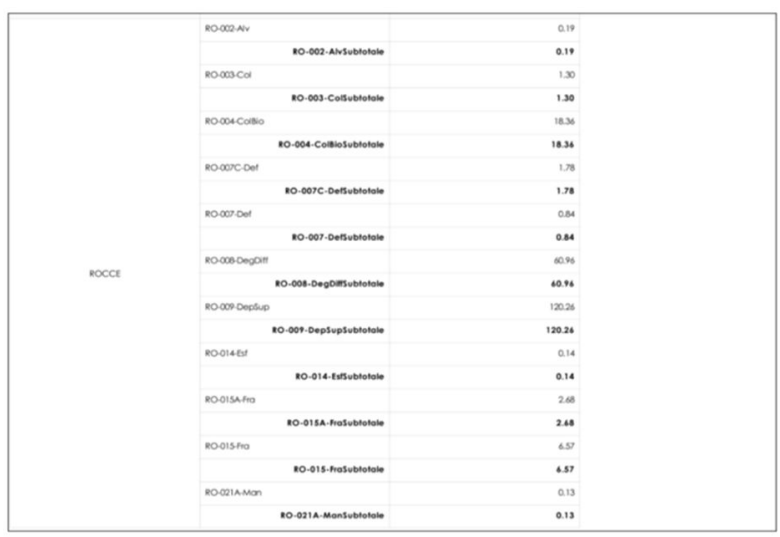

Figure 8. Part of a PDF report automatically generated by EasyCUBE PRO (calculation)

\section{THE CASE STUDY OF THE ARCHAEOLOGICAL SITE OF THE ROMAN RIVER PORT OF AQUILEIA}

The area of the Roman River port of Aquileia, which hinges between the forum and the eastern city perimeter along the river, constituted one of the fulcrum areas of the urban planning and the functional organization of the city in Roman times. It still represents a privileged area for the knowledge of the characteristics of Aquileia as a large port and commercial centre, landing point and sorting of a large quantity of goods of all kinds and of various provenances. 
On the same area there are also the wall curtains that laid Aquileia in different stages of his life: those of the Republican age and the fourth and fifth centuries, parallel to the river and partly overlapping the ancient docks, and the late antique a broken line, Perpendicular to the harbor. The site is therefore an essential element also for the knowledge of the defense systems that interested the city in the course of its history. It is therefore a context of absolute value for various aspects: environmental, topographical, urban, architectural, constructive, economic.

Moreover, the Roman fluvial port of Aquileia is the best preserved site among those of its kind: the object of continuous excavation campaigns, starting from the twenties of the last century, constitutes a laboratory of great importance, also for the experimentation of Advanced technologies and for the planning of maintenance, restoration and enhancement interventions.

\subsection{Application of the segmentation process}

The experience has had as object of study the archaeological site of the ancient Roman fluvial port of Aquileia: an area of great extension (about 25,000 square meters) and of undoubted interest, both from the archaeological and architectural point of view. Virtualgeo supplied the Advanced 3D model of this area, for which a complete restoration and its enhancement is planned in the future.

Regarding the work done by the architects students, in a first phase we defined the informative contents necessary for the subsequent elaborations, that is those related to the different types of materials present in the site under investigation, as well as to the alteration/degradation forms found, starting from the use of coded lexicons (UNI 11182/2006), appropriately integrated in relation to the specific characteristics of the site itself.

This in such a way that the collected data are homogeneous and coherent with each other, based on specific glossaries and univocal definitions able to describe in a textual form, albeit synthetically, the qualities of the elements represented in the model.

Subsequently to each category of homogeneous elements the relative quantitative data were associated, obtainable from the 3D model following its segmentation, or the "mapping", performed in such a way as to define the physical limits (twodimensional or three-dimensional, depending on the case) of these elements.

This operation then allowed, once defined the operations to be perform, to automatically quantify also the various conservation interventions envisaged for the manufactured article.

Each of the 36 students of the course worked on a quadrant of the area studied (about 200 square meters) on which he developed the mapping of the constituent elements and the forms of degradation present, as well as the quantification of the planned interventions. Each of them then developed specific simulations, using photo-editing programs, able to prefigure the outcome of the hypothesized interventions. During this experience it was also possible to test the EasyCUBE Pro software (Fig. 9), which Virtualgeo srl has adapted, during the process, to the specific needs that have emerged both during the analysis of the site and the definition of conservation interventions, but also in relation to the outputs that can be generated by the elaboration of the Advanced 3D model.

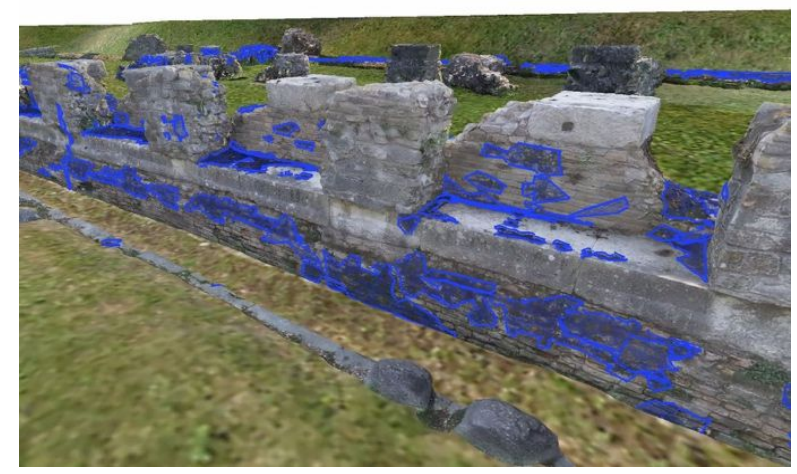

Figure 9. Example of a segmented area of the Roman river port of Aquileia (segmentation code RO-004-ColBio). Software: EasyCUBE PRO

\subsection{Final report and output of the metric and estimate calculations}

The experience has made it possible to pinpoint, and evenly, all the surfaces and volumes that had the same characteristics, first material and subsequently related to their state of preservation. Obviously the segmentations are in many cases overlapping, where more forms of alteration and/or degradation were presented at the same time.

The software used then allowed to generate automatically the reports relating to each type of segmentations adopted, associating the different materials to the individual forms of degradation identified.

At the same time, the conservation interventions to be foreseen for each case have been identified, verifying the possible outcomes through simulations carried out with photoretouching programs. This made it possible to verify beforehand their correctness, first in the didactic field and then comparing themselves with the principal (Aquileia Foundation) and the competent control body (Superintendency Archaeology, fine Arts and landscape of Friuli Venezia Giulia).

After their validation, the quantitative data deriving from the segmentations were associated with the relative interventions, on such a way as to obtain a real estimation metric calculation, divided between the fifteen sectors in which the area had been decomposed Archaeological.

Of course, each intervention entry has been associated with the relative unit of measure: MQ, MC or quantity. In The latter case, the segmentation was of punctual type, simply identifying the geometric centre of gravity of the element on which it should intervene.

Through the visualization tools of which the software is equipped, it was also possible to derive two-dimensional representations (horizontal and vertical sections) of a traditional type, suitable for paper printing that can be used on site, in Execution phase of the interventions.

\section{CONCLUSIONS}

The Advanced 3D procedure adopted in this experimentation has highlighted many advantages: the accuracy, the rapidity, the possibility to intervene at any time on the structure of the data and the different elements, as well as on their description and implementation, both textual and photographic.

What has not been possible to verify, given also the limited time of realization of the experience ( 3 months), is the actual flexibility of the methodology in relation to the temporal dimension. 
The degradation of materials in fact is a dynamic phenomenon, in some cases rapidly evolving, and requires a constant and continuous updating of the data relating to the state of preservation of a work. In the same way it is necessary to monitor it even after this has been the subject of a restoration operation. This is to verify the results that to program correctly (and update) the subsequent maintenance operations.

It would then be to construct an equally dynamic model, on which it is possible to compare the state of preservation of a work even at a distance of time, or to update it in case interventions were made, like those for example related to Fruition, which modify its morphology.

The possibility to realize Advanced 3D models of the same object at a distance of time is discounted, but it should be further experimented in order to define a technology of rapid and economical use, such as to become an instrument of common use to all the Operators in the sector, as it is already happening for the BIM regarding the new works of architecture and engineering.

\section{REFERENCES}

Canevese E.P., Tedeschi R., Mora P., 2008. The caves of Naica in 3D: Erminio Paolo Canevese and colleagues report on laser scanning and Cloudcube for Mexico's Naica caves, Geoconnexion International Magazine, July/ August 2008, Volume 7, Issue 7,

http://www.virtualgeo.eu/pdf2/A4\%202008Geoconnexion\%2 0International\%20Magazine.pdf

Canevese E.P., Tedeschi R., Forti P., 2009: The caves of Naica. Laser Scanning in extreme underground environments, The American Surveyor, February 2009,

http://www.virtualgeo.eu/pdf2/A10\%202009-

The $\% 20$ American\%20Surveyor.pdf

Canevese E.P., Forti P., Naseddu A., Ottelli L., Tedeschi R., 2011. Laser Scanning technology for the hypogean survey: The case of Santa Barbara karst system (Sardinia, Italy), http://www.virtualgeo.eu/pdf/A7\%202011-

Acta\%20Carsologica.pdf

Canevese E.P., De Gottardo T., 2017. Beyond point clouds and virtual reality - Innovative methods and technologies for the protection and promotion of cultural heritage, May 2017, https://www.geomaticscube.com/en/about/

Franceschi S., Germani L., 2007. Gli elaborati per l'analisi del progetto di restauro, Progettare Recupero n. 11-2007, http://www.build.it/allegati_news/ Franceschi.pdf

Geomaticscube, 2018: https://www.geomaticscube.com/

Olivieri M., 2018. Vantaggi e potenzialità dell'approccio HBIM per il progetto di restauro delle Pescherie di Giulio Romano, September 2018,

https://www.bimportale.com/vantaggi-potenzialitadellapproccio-hbim-progetto-restauro-delle-pescherie-giulioromano/

UACE, 2018. Measurement tools, https://www.uace.eu/battistero-concordia/geomatics/ 